\title{
Ozone Damages to Mediterranean Crops: Physiological Responses
}

\author{
Albino Maggio*, Massimo Fagnano \\ Dipartimento di Ingegneria Agraria e Agronomia del Territorio, Università di Napoli Federico II \\ Via Università 100, 80055 Portici (NA), Italy
}

Received: 8 January 2008. Accepted 28 January 2008.

\begin{abstract}
In this brief review we analyzed some aspects of tropospheric ozone damages to crop plants. Specifically, we addressed this issue to Mediterranean environments, where plant response to multiple stresses may either exacerbate or counteract deleterious ozone effects. After discussing the adequacy of current models to predict ozone damages to Mediterranean crops, we present a few examples of physiological responses to drought and salinity stress that generally overlap with seasonal ozone peaks in Southern Italy. The co-existence of multiple stresses is then analyzed in terms of stomatal vs. non-stomatal control of ozone damages. Recent results on osmoprotectant feeding experiments, as a non-invasive strategy to uncouple stomatal vs. non stomatal contribution to ozone protection, are also presented. In the final section, we discuss critical needs in ozone research and the great potential of plant model systems to unravel multiple stress responses in agricultural crops.
\end{abstract}

Key-words: stomatal conductance, salt stress, drought, osmoprotection, clover, alfalfa, tomato.

\section{Introduction}

The effect of ozone on Mediterranean crops is matter of recent debate since current models to predict ozone damages are not calibrated for this environment, where multiple abiotic stresses often co-exist during the time of maximum exposure to this air pollutant (Fumagalli et al., 2001; Ferretti et al., 2007; Maggio et al., 2007a). The interaction between ozone and other environmental stresses is mostly associated to a fundamental event: in order to cause toxicity, ozone must enter into the plant through the stomata. Therefore, any stress-induced stomatal closure may restrict ozone uptake and, consequently, it may interfere with its effects on plant tissues and cellular structures. Nevertheless, available models to describe ozone fluxes into the plant are generally based on vapour pressure deficit (VPD) and soil moisture as the only potential stress parameters (Jarvis, 1976). This may overestimate ozone damages in those conditions where other factors, such as the osmotic com- ponent of the soil water (salinity) may affect stomatal closure (Munns, 2002). Indeed, a reduced stomatal conductance is a quite common occurrence in spring/summer crops of coastal areas of Mediterranean regions and, in this environment, it may invalidate the output of prediction models that are based on ozone exposure rather than actual ozone uptake (Maggio et al., 2007a). To further complicate this picture, we should consider that, once ozone enters into the plant, it activates scavenging molecules and antioxidant compounds involved in Reactive Oxygen Species (ROS) detoxification responses (Sunkar et al., 2003; D'Haese et al., 2005). The level of these important metabolites for ozone detoxification is generally enhanced by abiotic stresses such as drought and salinity, typical of Mediterranean regions. Therefore, the stress-dependent stomatal- vs. non-stomatal control of ozone damages, necessarily requires a more detailed assessment of plant/ozone interactions for Mediterranean crops. Based on these considerations, we begun to characterize the re- 
sponse to ozone in a few crops grown in Southern Italy to highlight possible causes of interference between ozone damages and application of current prediction models to a typical Mediterranean environment. Published and unpublished data as well as future perspectives are reviewed in the following sections.

\section{Water stress and ozone damages}

An interesting example of the complex interactions between ozone damages and other environmental stresses has been documented by Merola and Fagnano (2006). Ozone damages were evaluated on wild ecotypes of perennial ryegrass (Lolium perenne L.) and white clover (Trifolium repens L.) collected in Sant'Angelo dei Lombardi (Avellino, Italy), a hilly area in the Southern Appennino mountains. Consociated ryegrass and clover plants were grown in 28 $\mathrm{cm}$ pots filled with soil and irrigated following the standard procedure described in UNECE (1998). Plants were exposed to 3 irrigation regimes: well watered (replenishment of $100 \%$ of the evapotranspired water), moderate water stress (replenishment of $66 \%$ ), severe water stress (replenishment of 33\%). Pots were located in charcoal filtered (FA) and not-filtered (NF) Open Top Chambers (OTC) to assess yield losses due to ozone (Fagnano et al., 2004). An open field control (Ambient Air, AA) was also included. During the experiment, the AOT 40 cumulated over 150 days was $16.7 \mathrm{ppm} \mathrm{h}$, in AA, $14.1 \mathrm{ppm} \mathrm{h}$ in NF and only $0.6 \mathrm{ppm} \mathrm{h}$ in FA. The ryegrass biomass production was not significantly reduced in the $66 \%$ irrigation treatment, whereas the mean fresh weight per plant was only $3.9 \mathrm{~g}$ at $33 \%$ irrigation vs. $7.3 \mathrm{~g}$ of the $100 \%$ irrigation control. Consistent with the results of Nussbaum et al. (1995) and Bermejo et al. (2003), ryegrass plants were insensitive to ozone since no differences were found between FA and NF plants. In contrast, clover was quite sensitive, since its biomass was approximately 5 times higher in absence of ozone (FA). Either a moderate $(66 \%)$ or a strong $(33 \%)$ water shortage dramatically reduced the clover plants biomass. However, water stress also cancelled the differences observed in control plants (100\% irrigation) grown in presence or absence of ozone. This response mirrored the drought ef- fects on stomatal conductance, which was almost twice in well watered plants, in absence of ozone. Similar results have been recently reported for soybean by Bou Jaoudè et al. (2008), who highlighted the effects of ozone on stomatal conductance in presence/absence of stress. In wellwatered conditions, an increased ozone concentration was shown to reduce the stomatal conductance whereas, upon water stress, high ozone levels did not further affect this parameter.

The clover sensitivity to ozone damages has been specifically analyzed by Fagnano and Merola (2007), who have compared the response to ozone in resistant and sensitive white clover ecotypes. Upon water stress, the ozoneinduced yield loss was reduced from $38 \%$ to $22 \%$ in the sensitive ecotype, whereas no interaction between ozone and water shortage was observed in the resistant one. Possible reasons for different ozone sensitivity of the two ecotypes were likely attributable to a reduced stomatal conductance of the resistant ecotype, which may have restricted ozone uptake and delayed its accumulation overtime. Indeed, ozone-dependent yield losses are positively correlated with the actual ozone uptake $\left(\mathrm{R}^{2}=0.99\right)(\mathrm{Fag}-$ nano et al., 2007). It is also worth mentioning that different irrigation techniques may drastically affect plant response to ozone toxicity. This is a critical issue that needs to be further investigated in order to realistically assess the magnitude of potential ozone damages for most common crop systems of specific environments. In Southern Italy, for example, even irrigated field crops may undergo a remarkable reduction in stomatal conductance (from 2.5-2.8 to 1.3-1.5 $\mathrm{cm} \mathrm{s}^{-1}$ in soybean) between two irrigation events (7-10 day interval) (Bou Jaoudè et al., 2008). Stomatal closure may also be transiently induced by partial root drying phenomena to which spring-summer crops are frequently exposed, or as a consequence of root anoxia that may occur right after an irrigation or an intense summer rainfall in heavy-clay soils, typical of Southern Italy (De Pascale et al., 2003; Issarakraisila et al., 2007).

\section{Salinity stress and ozone damages}

With a few exceptions, the interaction between tropospheric $\mathrm{O}_{3}$ concentration patterns and 
plant responses to salinity in Southern Italy, and similar areas exposed to salinization, has largely been overlooked. Alfalfa yield can be reduced up to $37.5 \%$ by ozone at low/moderate salinity (Fagnano et al., 2007). In contrast, no differences have been reported for plant grown in absence or presence of ozone upon irrigation with saline water $\left(4.4 \mathrm{~g} \mathrm{~L}^{-1}\right.$ of $\left.\mathrm{NaCl}\right)$. Similar results have been obtained with tomato plants exposed to salt stress, in presence/absence of ozone, to assess how salinity and ozone may actually interfere in terms of both physiological responses and final yield (Maggio et al., 2007a). In these experiments, tomato plants were grown in OTC located in a sub-urban area, where the average daily maximum $\mathrm{O}_{3}$ values over the growth season were 38 and $62 \mathrm{ppb}$ under FA and NF/AA conditions, respectively. On a subset of plants, salinization was accomplished by adding $\mathrm{NaCl}$ and $\mathrm{CaCl}_{2}(1: 2$ molar ratio) to tap water to a final electrical conductivity (EC) and osmotic potential $\left(\psi_{\pi}\right)$ of $7.0 \mathrm{dS} \mathrm{m}{ }^{-1}$ and $-0.25 \mathrm{MPa}$, respectively. FA plants had a greater total biomass and higher yield than ozonated ones. Nevertheless, these differences disappeared upon salinization (A. Maggio, M. Fagnano, unpublished results). These results should be interpreted on a relative basis since salinity by itself reduces growth in absence of ozone.

Nevertheless, the interaction between salinity-induced stomata closure and ozone responses may have important implications in terms of stomatal control of ozone damages. In addition, salt stress exposure caused an increase of the carotenoids content in tomato fruits. Although we cannot precisely quantify the contribution of these antioxidants in counteracting ozone damages, we must consider that salinity, as well as other abiotic stresses, may activate multiple detoxification functions, which will participate in defining the overall stress response to ozone in Mediterranean regions.

\section{Stomatal/non-stomatal control of ozone dam- ages}

As discussed in the previous sections, most adaptive responses to environmental stresses may counteract ozone damages by restricting the stomatal ozone intake and, consequently, by delaying the onset of a toxicity threshold. Con- sistently, a controlled induction of pre-adaptation mechanisms in crop species could also functionally compensate the effect of damages associated to ozone exposure. The accumulation of compatible solutes is certainly among the most documented plant responses to many abiotic stresses (Hasegawa et al., 2000). Compatible solutes are organic molecules usually produced to reduce the cellular water potential and to facilitate water uptake under water shortage and in hyper-osmotic environments (Rhodes and Hanson, 1993). Amino acids, some quaternary ammonium compounds and sugars that are ex-novo produced by stressed plants usually have this function. Some of these molecules have also been involved in other physiological processes, such as the control of cell division (Maggio et al., 2002a) and the detoxification of Reactive Oxygen Species (ROS) (Maggio et al., 2002b; Foyer, 2007).

Examples of induced stress pre-adaptation based on the functional physiology of compatible solutes exist in the literature. Increased levels of compatible solutes (osmoprotectans) have been obtained either through genetic engineering (Maggio et al., 2003; Zhang et al., 2004) or exogenous applications on vegetable and herbaceous crops with the aim of improving their performance under stress conditions (Heuer, 2003). The possibility of feeding proline to control the deleterious effects of osmotic stress has been documented in tomato (Makela et al., 1996). Applications of foliar glycinbetaine have also been performed on pea, tomato and some herbaceous species that do not synthesize glycinbetaine (Makela et al., 1996). Since the main effect of these molecules is to reduce the cellular osmotic potential and to promote water uptake and tissue hydration, it is also possible that under certain (non-stress) conditions, their accumulation would increase the stomatal conductance.

Based on these assumptions, we attempted to verify whether variations in stomatal conductance, obtained by feeding compatible solutes to the plant, would affect ozone uptake and could provide some insights into the stomatal vs. non stomatal control of ozone damages. In the spring-summer 2006, we performed an experiment to answer this question using a tomato crop grown in the OTC facility available at the experimental field of Agricultural Facul- 
ty (Portici - Parco Gussone) of the University of Naples Federico II. Tomato plants were transplanted in plastic buckets filled with soil and connected through a wick-system to a water reservoir for optimal water supply. Plants were then exposed to AA, FA (two OTC) or NF (two OTC) ozone regimes. In each OTC, the air recirculation was ensured by a ventilation system. For each environment (AA, FA, and NF), 48 plants (24 plants replicated twice) were treated with a solution of proline and exposed to salt stress. Proline was given to 12 plants for each replication in the form of $10 \mathrm{mM}$ aqueous solution $(200 \mathrm{~mL}$ final volume for each plant, given two times, one week apart), whereas 12 control plants received water only. Salt stress was imposed by adding $\mathrm{NaCl}$ and $\mathrm{CaCl}_{2}$ (1:2 molar ratio) to the irrigation water of 6 plants per replication, to obtain a final osmotic potential of the nutrient solution of $-0.15 \mathrm{MPa}\left(4.0 \mathrm{dS} \mathrm{m}^{-1}\right)$. At 28, 43 and 52 days from transplanting (DAT), the stomatal resistance was measured in the morning, at midday and in the afternoon with a diffusion porometer (AP-4, Delta-T Devices, Cambridge). At harvest, standard biometric and yield parameters were measured (Maggio et al., 2007b).

Salinity and ozone both increased the stomatal resistance (Tab. 1). In contrast, the proline treatment caused a $15 \%$ reduction of the stomatal resistance. During the warmest day hours (13:00), proline had an effect only in the absence of saline stress, which in turn caused a general increase of stomatal resistances and reduced the differences among treatments (Tab. 1; int. SxP). Upon salinization, the fruit yield per plant decreased $(-40 \%$ in AA and FA), with some beneficial effects of proline (Fig. 1). Specifically, in AA, proline caused a yield increase only in non salinized plants. Conversely, in absence of ozone, these results were reverted and the beneficial effects of proline were only apparent in the presence of salt stress (Fig. $1)$. Proline is a compatible solute that, when accumulates in plant tissues, may have different effects depending on other environmental variables that may affect water/solutes homeostasis. The co-existence of multiple abiotic stresses, such as salinity and ozone, has clearly interfered with the physiological function of proline. In the presence of ozone (which by itself activates stomatal closure) the effect of proline was ap-
Table 1. Effects of different treatments on stomatal resistance. $\mathrm{AA}=$ ambient air; $\mathrm{FA}=$ filtered air; NF $=$ non-filtered air. Within each column, n.s., $* * *=$ not significant and significant differences at $P \leq 0.05$ or 0.01 , respectively.

\begin{tabular}{lcccc}
\hline \multicolumn{5}{c}{ Time } \\
& $09: 00$ & $13: 00$ & $17: 00$ & mean \\
& $\mathrm{s} \mathrm{cm}^{-1}$ & $\mathrm{~s} \mathrm{~cm}^{-1}$ & $\mathrm{~s} \mathrm{~cm}^{-1}$ & $\mathrm{~s} \mathrm{~cm}^{-1}$ \\
\hline Ozone & & & & \\
$\mathrm{AA}$ & $0.99 \mathrm{~b}$ & $1.17 \mathrm{~b}$ & $1.10 \mathrm{~b}$ & $1.09 \mathrm{~b}$ \\
$\mathrm{AF}$ & $0.82 \mathrm{c}$ & $0.92 \mathrm{c}$ & $0.84 \mathrm{c}$ & $0.86 \mathrm{c}$ \\
$\mathrm{NF}$ & $1.42 \mathrm{a}$ & $1.78 \mathrm{a}$ & $1.54 \mathrm{a}$ & $1.58 \mathrm{a}$ \\
& $* *$ & $* *$ & $* *$ & $* *$ \\
Salt & & & & \\
$-\mathrm{S}$ & 0.85 & 1.01 & 0.95 & 0.94 \\
$+\mathrm{S}$ & 1.30 & 1.57 & 1.38 & 1.42 \\
& $* *$ & $* *$ & $* *$ & $* *$ \\
Proline & & & & \\
$-\mathrm{P}$ & 1.12 & 1.44 & 1.24 & 1.27 \\
$+\mathrm{P}$ & 1.03 & 1.14 & 1.08 & 1.08 \\
& $* *$ & $* *$ & $* *$ & $* *$ \\
Interactions & & & & $* *$ \\
AxS & n.s. & $* *$ & $*$ & $* *$ \\
AxP & n.s. & $* *$ & $*$ & $* *$ \\
SxP & $*$ & $* *$ & n.s. & $* *$ \\
AxSxP & n.s. & $* *$ & $* *$ & $* *$ \\
\hline & & & &
\end{tabular}

parent only without an additional saline stress. However, the superimposition of multiple stresses flattened down the effects of proline on stomatal aperture and yield (Fig. 1, FA). The absence of ozone (FA), partially relieved (respect to NF) the stress to salinized plants, which consequently showed some positive response to proline. Consistently, the minimal stress exposure of non-salinized-non-ozonated plants presumably caused a positive water balance in these plants that turned out to be not (or minimally) receptive to an additional osmoprotective proline treatment. In NF plants, a general yield reduction was observed with deleterious effects of proline in salinized plants. This was again most likely associated to an overlapping of multiple stresses in NF OTCs (ozone plus high temperature), which may have been exacerbated by a further osmotic stress or an impaired stomatal control of plant water homoeostasis caused by proline. It is worth mentioning, however, that the response observed in FA indicates that proline, in addition to fine-tune cellular osmotic relations, may also counteract ozone damages through a mechanism that does not involve the control of stomatal ozone fluxes, since in $+\mathrm{P} /+\mathrm{S}$ plants the stomatal resistance was actually higher compared to $-\mathrm{P} /+\mathrm{S}$ plants (data not shown). 

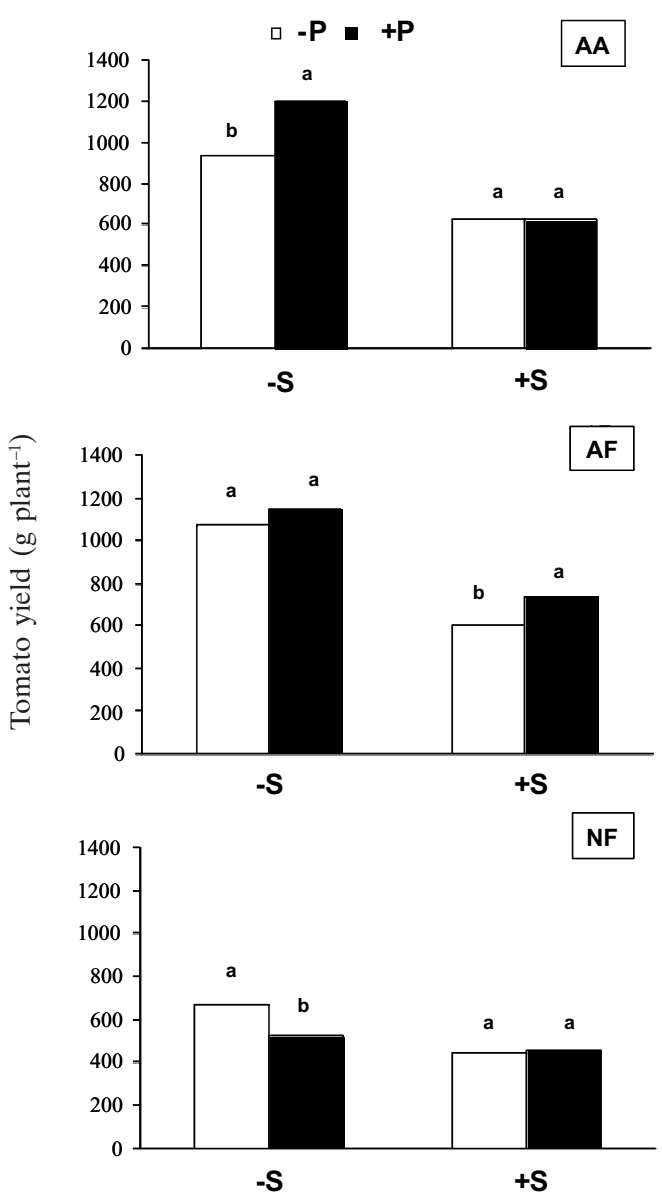

Figure 1. Interaction between salinity $(\mathrm{S})$ and proline $(\mathrm{P})$ treatments in presence/absence of ozone. AA = Ambient Air; FA = Filtered Air; NF $=$ Non-Filtered Air. Within each salinity treatment, different letters indicate significant differences at $P \leq 0.05$.

These results highlight the agronomic significance of photosyntates partitioning in response to several stresses, including ozone, for agricultural crops. Maggio et al., (2007a) pointed out that assessing the economic impact of ozone phytotoxicity is relatively simple when acute visible ozone injury can be demonstrated, like for leafy crops such as spinach, lettuce, and chicory (Klumpp et al., 2002). However, such assessment may be more complicated when the commercial part of the plant is represented by fruits or roots. Overall, proline treatment seemed to be an effective tool to test hypotheses on stomatal vs. non-stomatal contribution in ozone responses, which is particular relevant for Mediterranean crops.

\section{Future perspectives: using model systems to unravel multiple stress responses}

The analysis of the published literature on ozone effects on crop plants and current research programs highlighted three major needs: 1) reliable models to predict ozone damages must be further developed; 2) we have to improve our current knowledge on the physiological mechanisms of ozone uptake/detoxification and define toxicity thresholds; 3) we must unravel the complex interactions between ozone and other abiotic/biotic stresses. Model analysis able to realistically predict the damage to crop species in different environments should be clearly revised and calibrated to different environments. It has been generally acknowledged that damage assessments based on the actual amount of ozone uptake should replace those related to ozone exposure, which clearly present critical limitations, especially for those regions (Mediterranean) where stomatal conductance is very much affected by environmental constraints other than ozone (Ferretti et al., 2007; Maggio et al., 2007a). For agricultural systems, this scenario is further complicated by the necessity of referring ozone damages to both yield quantity and quality rather than total biomass, which may instead have some relevance to forest systems.

In this context, the effect of ozone should not be exclusively estimated as lesions and leaf damages, but also based on a less straightforward assessment of ozone effects on photosyntates translocation/accumulation, cell division/ expansion and nutritional value, which all contribute to define the yield of fruits and underground edible organs. This new level of complexity can be approached by analyzing both metabolic players and physiological responses that define plant response to ozone. A thorough analysis of the effects of chronic ozone exposure on gene expression has been recently reported by Li et al. (2006). Different ecotypes of Arabidopsis thaliana [Columbia-0, Wassilewskija, Cape Verde Islands] and the relative "extremophile" Thellungiella halophila were exposed to $20-25 \%$ over ambient ozone (an increase that is expected in the near future) to understand the metabolic components involved in ozone stress responses. Sensitive ecotypes (Columbia-0 and Wassilewskija) developed foliar le- 
sions within 10 days under increasing ozone while the ecotype Cape Verde Islands and Thellungiella halophila had a slower growth rate. Microarray analysis revealed that the sensitive ecotypes presented the largest number of changes in gene expression upon ozone exposure. In contrast, Thellungiella halophila, an Arabidopsis relative extremely tolerant to drought, salinity and cold stress, showed the least changes in gene expression, indicating a constitutive adaptation state, likely responsible also for ozone resistance. Major changes in gene expression referred to five categories: 1) antioxidant functions; 2) hormone-related genes, 3) transcription factors; 4) arabinogalactans (AGPS), receptorlike kinases (RLKS), mitogen-activated protein kinases (MAPKS) and the cell wall-membrane continuum; 5) Senescence. A critical role was attributed to the complex relationship between the behaviour of multiple redox-sensing pathways and differential ROS-tolerance across the ecotypes, as the basis for ozone tolerance.

In addition to microarray and gene expression profiling, mutational analysis may also provide new insights in the mechanisms governing ozone tolerance. Mutants of Arabidopsis thalia$n a$ and other plant models can be used to address specific questions in ozone research. Ozone exposure experiments using Arabidopsis mutant plants with a reduced ABA level and impaired stomatal regulation (Iuchi et al., 2001; Ruggiero et al., 2004) or with low ascorbate content (Conklin et al., 1996) may provide important information on the relative significance of ozone uptake and detoxification in determining the toxicity threshold.

\section{Conclusions}

Research on ozone effects on forests and crop plants started a few decades ago, nevertheless it has only recently been specifically addressed to Mediterranean environments. For these regions, it is essential to define reliable criteria to realistically assess the potential consequences of an increasing tropospheric ozone concentration for crop yield and quality. This is critical to provide to EU legislators a complete analysis on ozone responses of Southern vs. Central and Northern Europe crops since this will surely show remarkable differences that may substantially af- fect the significance of environmental plant toxicity levels recently issued by the EU commission. Although ozone may not be the major yield constraint for Mediterranean areas, it is also important to improve our knowledge on the fundamental mechanisms that mediate ozone uptake and damage and how these may enhance sensitivity to other abiotic stresses that usually impair crop yield in these environments.

\section{References}

Bermejo V., Gimeno B.S., Sanz J., de la Torre D., Gil J.M. 2003. Assessment of the ozone sensitivity of 22 native plant species from Mediterranean annual pastures based on visible injury. Atmospheric Environment, 37:4667-4677.

Bou Jaoudè M., Katerji N., Mastrorilli M., Rana G. 2008. Analysis of the effect of ozone on soybean in the Mediterranean region I. The consequences on cropwater status. European Journal of Agronomy, in press.

Conklin P.L., Willlams E.H., Last R.L. 1996. Environmental stress sensitivity of an ascorbic acid-deficient Arabidopsis mutant. Proceedings of the National Academy of Sciences of USA, 93:9970-9974.

De Pascale S., Maggio A., Barbieri G., Ruggiero C. 2003. Growth, water relations, and ion content of field grown celery under saline irrigation (Apium graveolens L. var. dulce [Mill.] pers.). Journal of American Society for Horticultural Science, 128:136-143.

D'Haese D., Vandermeiren K., Asard H., Horemans N. 2005. Other factors than apoplastic ascorbate contribute to the differential ozone tolerance of two clones of Trifolium Repens L. Plant Cell Environment, 28:623-632.

Fagnano M., Merola G., Forlani A., Postiglione L., Fuhrer J. 2004. Monitoring yield loss from ozone pollution in a Mediterranean environment: a comparison of methods. Water Air Soil Pollution, 155:383-398.

Fagnano M., Merola G. 2007. Ozone and water stress: effects on the behaviour of two white clover biotypes. Italian Journal of Agronomy, 2:3-12.

Fagnano M., Merola G., Cefariello R. 2007. Risposta dell'erba medica all'inquinamento da ozono con livelli crescenti di stress salino. Atti XXXVII Convegno Nazionale Società Italiana di Agronomia "Il contributo della ricerca agronomica all'innovazione dei sistemi colturali mediterranei", 13-14 settembre 2007, Catania, 331-332.

Fagnano M., Maggio A., Fumagalli I. 2008. Crops responses to ozone in Italy. Environmental Pollution, submitted.

Ferretti M., Fagnano M., Amoriello T., Badiani M., Ballarin-Denti A., Buffoni A., Bussotti F., Castagna A., Cieslik S., Costantini A., De Marco A., Gerosa G., Lorenzini G., Manes F., Merola G., Nali C., Paoletti 
E., Petriccione B., Racalbuto S., Rana G., Ranieri A., Tagliaferri A., Vialetto G., Vitale M. 2007. Measuring, modelling and testing ozone exposure, flux and effects on vegetation in southern European conditions. What does not work? A review from Italy. Environmental Pollution, 146:648-658.

Foyer C. 2007. Redox metabolism in plants and its role in programmed cell death and senescence. Comparative Biochemistry and Physiology A-Molecular \& Integrative Physiology 146 (4):S53-S53 2 Suppl. S.

Fumagalli I., Gimeno B., Velissariou D., De Temmerman L., Mills G. 2001. Evidence of ozone induced adverse effects on crops in the Mediterranean Region. Atmospheric Environment, 35:2583-2587.

Hasegawa P.M., Bressan, R.A., Zhu J.K., Bohnert H.J. 2000. Plant cellular and molecular responses to high salinity. Annual Review of Plant Physiology and Plant Molecular Biology, 51:463-499.

Heuer B. 2003. Influence of exogenous application of proline and glycinebetaine on growth of salt-stressed tomato plants. Plant Science, 165:693-699.

Issarakraisila M., Ma Q., Turner D.W. 2007. Photosynthetic and growth responses of juvenile Chinese kale (Brassica oleracea var. alboglabra) and Caisin (Brassica rapa subsp. parachinensis) to waterlogging and water deficit. Scientia Horticulturae, 111:107-113.

Iuchi S., Kobayashi M., Taji T., Naramoto M., Seki M., Kato T., Tabata S., Kakubari Y., Yamaguchi-Shinozaki K., Shinozaki K. 2001. Regulation of drought tolerance by gene manipulation of 9-cis-epoxycarotenoid dioxygenase, a key enzyme in abscisic acid biosynthesis in Arabidopsis. Plant Journal, 27:325-333.

Jarvis P.G. 1976. The interpretation of the variations in leaf water potential and stomatal conductance found in canopies in the field. Philosophical Transactions of the Royal Society of London Ser. B: Biological Sciences, 273:593-610.

Klumpp A., Ansel A., Klumpp G., Belluzzo N., Calatayud V., Chaplin N., Garrec J.P., Gutsche H.-J., Hayes M., Hentze H.-W., Kambezidis H., Laurent O., Penuelas J., Rasmussen S., Ribas Ro-Poulsen H., Rossi S., Sanz M.J., Shang H., Sifakis N., Vergne P. 2002. EuroBionet: a pan-European biomonitoring network for urban air quality assessment. Environmental Science and Pollution Research, 9:199-203.

Li P., Mane S.P., Sioson A.A., Vasquez Robinet C., Heath L.S., Bohnert H.J., Grene R. 2006. Effects of chronic ozone exposure on gene expression in Arabidopsis thaliana ecotypes and in Thellungiella halophila. Plant, Cell and Environment, 29:854-868.

Maggio A., Miyazaki S., Veronese P., Fujita T., Ibeas J.I., Damsz B., Narasimhan M.L., Hasegawa P.M., Joly R.J., Bressan R.A. 2002a. Does Proline Accumulation Play an Active Role in Stress-induced Growth Reduction? The Plant Journal, 31:699-712.

Maggio A., McCully M.G., Kerdnaimongkol K., Bressan R.A., Hasegawa P.M., Joly R.J. 2002b. The ascorbic acid cycle mediates signal transduction leading to stress-induced stomatal closure. Functional Plant Biology, 29:845-852.

Maggio A., Bressan R.A., Ruggiero C., Xiong L., Grillo S. 2003. Salt tolerance: placing advances in molecular genetics into a physiological and agronomic context. In: Sanità di Toppi L., Pawlik-Skowro_ska B. (eds.): Abiotic Stresses in Plants, 53-69. Kluwer Academic Publisher, The Netherlands.

Maggio A., De Pascale S., Fagnano M., Barbieri G. 2007a. Can salt stress-induced physiological responses protect tomato crops from ozone damages in Mediterranean environments? European Journal of Agronomy, 26:454-461.

Maggio A., De Pascale S., Martino A., Fagnano M. 2007b. Controllo stomatico dei danni da ozono. Atti XXXVII Convegno Nazionale SIA "Il contributo della ricerca agronomica all'innovazione dei sistemi colturali mediterranei", 13-14 Settembre 2007, Catania, 357-358.

Makela P., Peltonen-Sainio P., Jokinen K., Pehu E., Setala H., Hinkkanen R., Somersalo S. 1996. Uptake and translocation of foliar-applied glycinebetaine in crop plants. Plant Science, 121:221-230.

Merola G., Fagnano M. 2006. Interaction between stresses typical of the Mediterranean area: Ozone damages and water stress on Trifolium repens and Lolium perenne. In: Wieser G., Tausz M. (eds.): Critical levels of ozone: further applying and developing the fluxbased concept, 289-292. BFW, Vienna.

Munns R. 2002. Comparative physiology of salt and water stress. Plant Cell Environment, 25:239-250.

Nussbaum S., Geissmann M., Fuhrer J. 1995. Ozone exposure-response relationships for mixtures of perennial ryegrass and white clover depend on ozone exposure patterns. Atmospheric Environment, 29:989995.

Rhodes D., Hanson A.D. 1993. Quaternary ammonium and tertiary sulfonium compounds in higher-plants. Annual Review of Plant Physiology and Plant Molecular Biology, 44:357-384.

Ruggiero B., Koiwa H., Manabe Y., Quist T.M., Inan G., Saccardo F., Joly R.J., Hasegawa P.M., Bressan R.A., Maggio A. 2004. Uncoupling the effects of ABA on plant growth and water relations: Analysis of stol/nced3, ABA deficient salt stress tolerant mutant in Arabidopsis thaliana. Plant Physiology, 136:3134-3147.

Sunkar R., Bartels D., Kirch H.H. 2003. Overexpression of a stress-inducible aldehyde dehydrogenase gene from Arabidopsis thaliana in transgenic plants improves stress tolerance. Plant Journal, 35:452-464.

UNECE 1998. 'ICP-Crops Experimental Protocol', Report, ICP - Crops Coordination Centre, Institute of Terrestrial Ecology, Bangor (UK). http://icpvegetation.ceh.ac.uk/.

Zhang J.Z., Creelman R.A., Zhu J.K. 2004. From laboratory to field. Using information from Arabidopsis to engineer salt, cold, and drought tolerance in crops. Plant Physiology, 135:615-621. 